\title{
Incidence and progression of mild aortic regurgitation after Tirone David reimplantation valve-sparing aortic root replacement
}

\author{
Elizabeth H. Stephens, MD, PhD, ${ }^{a}$ David H. Liang, MD, PhD, ${ }^{b}$ John-Peder Escobar Kvitting, MD, PhD, ${ }^{a}$ \\ Fabian A. Kari, MD, ${ }^{a}$ Michael P. Fischbein, MD, PhD, ${ }^{a}$ R. Scott Mitchell, MD, ${ }^{a}$ and D. Craig Miller, MD ${ }^{\mathrm{a}}$
}

Objective: The study objective was to determine whether recurrent or residual mild aortic regurgitation, which occurs after valve-sparing aortic root replacement, progresses over time.

Methods: Between 2003 and 2008, 154 patients underwent Tirone David-V valve-sparing aortic root replacement; 96 patients $(62 \%)$ had both 1-year (median, $12 \pm 4$ months) and mid-term (62 \pm 22 months) transthoracic echocardiograms available for analysis. Age of patients averaged $38 \pm 13$ years, $71 \%$ were male, $31 \%$ had a bicuspid aortic valve, $41 \%$ had Marfan syndrome, and 51\% underwent aortic valve repair, predominantly cusp free margin shortening.

Results: Forty-one patients ( $43 \%$ ) had mild aortic regurgitation on 1-year echocardiogram. In $85 \%$ of patients $(\mathrm{n}=35)$, mild aortic regurgitation remained stable on the most recent echocardiogram (median, $57 \pm 20$ months); progression to moderate aortic regurgitation occurred in 5 patients $(12 \%)$ at a median of $28 \pm 18$ months and remained stable thereafter; severe aortic regurgitation developed in 1 patient, eventually requiring reoperation. Five patients $(5 \%)$ had moderate aortic regurgitation at 1 year, which did not progress subsequently. Two patients $(2 \%)$ had more than moderate aortic regurgitation at 1 year, and both ultimately required reoperation.

Conclusions: Although mild aortic regurgitation occurs frequently after valve-sparing aortic root replacement, it is unlikely to progress over the next 5 years and should not be interpreted as failure of the valve-preservation concept. Further, we suggest that mild aortic regurgitation should not be considered nonstructural valve dysfunction, as the 2008 valve reporting guidelines would indicate. We need 10- to 15-year follow-up to learn the long-term clinical consequences of mild aortic regurgitation early after valve-sparing aortic root replacement. (J Thorac Cardiovasc Surg 2014;147:169-78)

Supplemental material is available online.

In patients with aortic root pathology and good aortic valve cusp integrity, valve-sparing aortic root replacement (V-SARR) offers an attractive alternative to a conventional composite valve graft (CVG) with a mechanical or bioprosthetic valve. Valve-sparing procedures alleviate the need for anticoagulation with mechanical valves and minimize the risk of early structural valve deterioration in young patients receiving bioprosthetic valves. Although these factors make V-SARR appealing, a key question in

\footnotetext{
From the Department of Cardiovascular and Thoracic Surgery, ${ }^{\mathrm{a}}$ and Division of Cardiovascular Medicine, ${ }^{\mathrm{b}}$ Stanford University School of Medicine, Stanford, Calif.

Disclosures: Authors have nothing to disclose with regard to commercial support.

Read at the 93rd Annual Meeting of The American Association for Thoracic Surgery, Minneapolis, Minnesota, May 4-8, 2013.

Received for publication June 11, 2013; revisions received Aug 24, 2013; accepted for publication Sept 4, 2013; available ahead of print Oct 31, 2013

Address for reprints: D. Craig Miller, MD, Department of Cardiovascular and Thoracic Surgery, Falk Cardiovascular Research Center, Stanford University School of Medicine, Stanford, CA 94305-5247 (E-mail: dcm@stanford.edu). $0022-5223 / \$ 36.00$

Copyright (c) 2014 by The American Association for Thoracic Surgery http://dx.doi.org/10.1016/j.jtcvs.2013.09.009
}

deciding the best operative strategy is the expected durability of the repair and identifying which patients are at higher risk for failure. One of the risk factors predictive of V-SARR failure is postoperative aortic regurgitation (AR), which can progress and require reoperation. ${ }^{1-4}$ Previous reports have focused on postoperative AR and reoperation; however, whether mild AR early after V-SARR progresses has not been completely assessed. In an elegant study from Hans Sievers' group in Lübeck, Germany, by Hanke and colleagues, ${ }^{1}$ progression of AR was analyzed after 2 types of V-SARR: Yacoub remodeling $(\mathrm{n}=108)$ and Tirone David reimplantation $(\mathrm{n}=83)$. After a median follow-up of 2.3 years, factors associated with progression of AR included Marfan syndrome (MFS), aortic valve repair (central plication with pericardial pledgets), and preoperative annular diameter. ${ }^{1}$ The present study sought to expand on those results over a longer period of time in patients who underwent a Tirone David-V Stanford modification V-SARR procedure.

\section{MATERIALS AND METHODS}

\section{Study Cohort}

From 2003 to 2008, 154 patients underwent Tirone David-V Stanford modification V-SARR; 96 patients $(62 \%)$ had both a 1-year follow-up transthoracic echocardiogram (TTE) (median, $12 \pm 4$ months after V-SARR; interquartile range [IQR], 9-14 months) and a recent, mid-term TTE (median, 


\section{Abbreviations and Acronyms \\ $\mathrm{AI} \quad=$ aortic insufficiency \\ AR = aortic regurgitation \\ $\mathrm{BAV}=$ bicuspid aortic valve \\ CTD = connective tissue disorder \\ CVG = composite valve graft \\ $\mathrm{IQR} \quad=$ interquartile range \\ MFS = Marfan syndrome \\ $\mathrm{TAV}=$ trileaflet aortic valve \\ TTE $=$ transthoracic echocardiogram \\ $\mathrm{V}$-SARR $=$ valve-sparing aortic root replacement}

$62 \pm 22$ months after V-SARR; IQR, 44-82 months) and constituted the study cohort. For patients with AR progression beyond 1 year, which was defined as an increase in 1 or more AR grades, intervening TTEs were graded to determine when the valve deteriorated. Clinical follow-up for all 96 patients ranged from 1.8 to 9.2 years (mean, $5.3 \pm 1.8$ years; median, $5.2 \pm 1.8$; IQR, 3.7-6.8 years), totaled 487 patient-years, and was $100 \%$ complete.

All TTE images were evaluated by a single American Society of Echocardiography Level III trained echocardiographer (D. H. L.); degree of AR was graded semiquantitatively on a scale from 0 to $4+$ based on jet width according to standard criteria. ${ }^{5}$ Quantitative methods, such as quantitative Doppler and effective regurgitant orifice, could not be used because of the disparate sources of echocardiography images and eccentric AR jets. Where possible, AR grade of moderate or more was corroborated by reversal of flow in the distal arch or descending aorta.

For comparison purposes, the total cohort was divided into 2 subgroups: those with and those without mild AR on the 1-year TTE. Subset analysis was then performed on the patients with early mild AR that subsequently worsened. Because of early failure associated with the use of neo-suspensory chords in patients with a bicuspid aortic valve (BAV), ${ }^{6,7}$ an additional set of analyses was performed excluding the 2 patients with neo-suspensory chords.

\section{Operative Procedure}

The Stanford modification of the Tirone David-V V-SARR procedure has been described. ${ }^{8}$ Depending on the extent of the aneurysm, total or partial arch replacement using the "Peninsula technique" in patients with a BAV was performed as described previously. ${ }^{9}$

\section{Statistical Analysis}

The preoperative and intraoperative characteristics listed in Tables 1 and 2 were compared between groups using chi-square tests for nominal and ordinal variables, and general linear model multivariate analysis for scalar variables. Factors found to have a $P$ value less than .25 on multivariate analysis for predicting AR progression were assessed using log-rank (Mantel-Cox) analysis and nonparametric Kaplan-Meier actuarial curves. Cox proportional-hazard regression analysis was attempted, but the model was unstable because of an inadequate number of adverse events. All statistical testing was performed using commercially available software (SPSS Statistics 21; SPSS, IBM, New York, NY). Data are reported as median or mean \pm 1 standard deviation; IQR are included when appropriate. The Stanford institutional review board approved the study, and informed consent was obtained from the patients at time of contact.

\section{RESULTS}

\section{Preoperative and Intraoperative Characteristics}

The average age of the total cohort $(\mathrm{n}=96)$ was $38 \pm 13$ years (IQR, 27-48 years), $71 \%$ were male, $31 \%$ had a BAV, and $41 \%$ had MFS. Patients with a BAV were further subdivided using the classification system by Sievers and Schmidtke, ${ }^{10}$ with the majority being Sievers' $1 / \mathrm{L}-\mathrm{R}^{10}$ (Table 1).

There were no statistically significant differences between the subgroups with or without early mild AR in terms of age, incidence of connective tissue disorder (CTD), incidence of BAV, or preoperative AR grade. There were significantly more male patients in the subgroup without early mild AR compared with the subgroup with early mild $\mathrm{AR}(P=.012)$, and this subgroup was correspondingly taller $(P=.044)$. Arch replacement was performed in 30 patients ( $31 \%$, Table 2$)$, and aortic valve repair was performed in 49 patients $(51 \%$, free margin shortening in all except 2 patients, raphé resection in 5 patients with BAV, and neo-suspensory chord creation in 2 patients with BAV). Preoperative and postoperative annular diameters, as well as magnitude of annular diameter change, were not significantly different between the subgroups, nor was the need for concomitant aortic valve repair. Mild AR on predischarge TTE was evident in $17 \%$ of patients in the subgroup with mild AR on 1-year TTE, which was significantly higher than in the subgroup with no AR on 1 -year TTE $(0 \%, P=.003)$. Timing of the 1 -year TTE was not different between subgroups; however, the time interval between V-SARR and the most recent mid-term TTE was significantly longer in the subgroup without early mild AR (74 \pm 21 months vs $53 \pm 20$ months, $P=.008$, Table 3 ).

\section{Incidence and Progression of Postoperative Aortic Regurgitation}

Forty-one patients $(43 \%$, Figure 1$)$ had mild AR on the 1-year TTE; of this subgroup, 35 patients ( $85 \%$ ) continued to have mild AR on most recent TTE (median, $57 \pm 20$ months; IQR, 40-73 months) and were included in the "mild stable AR" subset. The mild AR in 5 patients $(12 \%)$ progressed to moderate AR at a median of $28 \pm 18$ months (IQR, 27-38 months), which remained stable thereafter (median follow-up, $44 \pm 27$ months; IQR, 38-49 months). These 5 patients plus 1 patient with $\mathrm{AR}$ that progressed to severe $\mathrm{AR}$ requiring reoperation were included in the "progression of mild AR" subset for comparison purposes. Among the patients in the "progression of mild AR" subset, AR grade increased at a median of $28 \pm 17$ months (IQR, 22-36 months) postoperatively. Of note, only 1 patient $(2 \%)$ with mild AR on 1-year TTE had progression to greater than moderate AR over the 53-month follow-up period.

Five patients $(5 \%)$ had moderate AR on the 1-year TTE, but the degree of AR did not progress subsequently over a median follow-up of $49 \pm 28$ months (IQR, 46-95 months). Four of these patients initially had mild AR, and 1 patient had no AR on the predischarge TTE. Two patients $(2 \%)$ had more than moderate AR on the 1-year TTE (both ultimately 
TABLE 1. Preoperative patient characteristics

\begin{tabular}{|c|c|c|c|c|}
\hline & Total cohort (96 patients) & No early AR $(47,49 \%)$ & Mild early AR $(41,43 \%)$ & $P$ value \\
\hline Age (y) & $38 \pm 13(27-48)$ & $36 \pm 12(27-45)$ & $40 \pm 13(29-50)$ & .155 \\
\hline Gender, male & $68(71 \%)$ & $38(81 \%)$ & $23(56 \%)$ & .012 \\
\hline Weight (lb) & $179 \pm 41(158-199)$ & $186 \pm 43(165-203)$ & $175 \pm 35(157-197)$ & .189 \\
\hline Height (in) & $72 \pm 5(69-75)$ & $73 \pm 4(69-75)$ & $71 \pm 4(69-74)$ & .044 \\
\hline BMI $\left(\mathrm{kg} / \mathrm{m}^{2}\right)$ & $24 \pm 5(21-28)$ & $25 \pm 6(21-28)$ & $24 \pm 4(22-27)$ & .759 \\
\hline $\operatorname{BSA}\left(\mathrm{m}^{2}\right)$ & $2.0 \pm 0.3(1.9-2.2)$ & $2.1 \pm 0.2(2.0-2.2)$ & $2.0 \pm 0.2(1.9-2.2)$ & .086 \\
\hline BAV (Sievers' type): & $30(31 \%)$ & $11(23 \%)$ & $14(34 \%)$ & .265 \\
\hline 0-AP & $4(4 \%)$ & $2(4 \%)$ & $2(5 \%)$ & \\
\hline 0 -LAT & $3(3 \%)$ & $1(2 \%)$ & $2(5 \%)$ & \\
\hline 1-L-R & $21(22 \%)$ & $8(17 \%)$ & $9(22 \%)$ & \\
\hline $1-\mathrm{N}-\mathrm{L}$ & $1(1 \%)$ & $0(0 \%)$ & $1(2 \%)$ & \\
\hline $1-\mathrm{R}-\mathrm{N}$ & $1(1 \%)$ & $0(0 \%)$ & $0(0 \%)$ & \\
\hline CTD: & $41(43 \%)$ & $23(49 \%)$ & $16(39 \%)$ & .350 \\
\hline MFS & $39(41 \%)$ & $22(47 \%)$ & $15(37 \%)$ & \\
\hline Loeys-Dietz syndrome & $2(2 \%)$ & $1(2 \%)$ & $1(2 \%)$ & \\
\hline Preoperative AR: & & & & .521 \\
\hline None/trivial & $36(38 \%)$ & $22(47 \%)$ & $14(34 \%)$ & \\
\hline Mild (1+) & $28(29 \%)$ & $14(30 \%)$ & $12(29 \%)$ & \\
\hline Moderate $(2+)$ & $18(19 \%)$ & $8(17 \%)$ & $10(24 \%)$ & \\
\hline Moderate-severe (3+) & $0(0 \%)$ & $0(0 \%)$ & $0(0 \%)$ & \\
\hline Severe $(4+)$ & $14(15 \%)$ & $3(6 \%)$ & $5(12 \%)$ & \\
\hline $\operatorname{LVEF}(\%)$ & $61 \pm 6(58-65)$ & $60 \pm 7(55-65)$ & $62 \pm 4(60-65)$ & .096 \\
\hline Aortic dissection & $1(1 \%)$ & $1(2 \%)$ & $0(0 \%)$ & .348 \\
\hline Previous cardiac surgery & $2 *(2 \%)$ & $2 *(4 \%)$ & $0(0 \%)$ & .182 \\
\hline
\end{tabular}

Data are presented as mean \pm 1 standard deviation with IQR in parentheses. For parametric variables, the total number of patients with the given characteristic is given followed by the percentage of the group in parentheses. The first column lists data for the total study cohort (all 96 patients); data for the "no early AR" and "mild early AR" groups are listed in the following 2 columns. For each group, the number of patients and percentage of the total study cohort ( 96 patients) are indicated in parentheses. $P$ values listed are for the comparisons between the "no early AR" and "mild early AR" groups. BAVs were classified using the classification system by Sievers and Schmidtke, ${ }^{10}$ where O indicates no raphé and includes the subtypes of 0-AP and 0-LAT, and 1 indicates 1 raphé and includes the subtypes of 1-L-R, 1-N-L, and 1-R-N. AP, Anterior-posterior; AR, aortic regurgitation; $B A V$, bicuspid aortic valve; $B M I$, body mass index; $B S A$, body surface area; $C T D$, connective tissue disorder; $L A T$, lateral; $L V E F$, left ventricular ejection fraction; $M F S$, Marfan syndrome; $1-N-L$, noncoronary cusp and left coronary cusp fusion; $1-L-R$, left-right coronary cusp fusion; $1-R-N$, right coronary cusp and noncoronary cusp fusion. *Both patients had previous coarctation repairs.

required reoperation); both had mild AR on the predischarge TTE. No patient had 4+ AR on the 1-year TTE.

\section{Predictors of Progression of Mild Early Aortic Regurgitation}

Multivariate analysis identified aortic valve repair $(P=.007)$, preoperative AR grade $(P=.014)$, and specifically preoperative $4+\operatorname{AR}(P=.002)$ to be related to progression of early mild AR. Variables with a $P$ value less than .5 in the multivariate analysis (arch repair, innominate cannulation, preoperative annular diameter, CTD, gender, aortic valve repair, preoperative severe AR, and preoperative AR grade) were entered into the actuarial log-rank analysis. Aortic valve repair, preoperative AR grade, and $4+$ preoperative AR correlated significantly with progression of mild AR (aortic valve repair: $P=.006$, preoperative AR grade: $P=.003$, severe preoperative AR: $P<.001$ ) (Figure E1). Predischarge AR was not a significant predictor of AR progression on multivariate analysis $(P=.252)$ or log-rank analysis $(P=.919)$. Aortic valve repair and preoperative AR were entered into a Cox proportional-hazards analysis, but the model was found to be unstable. On the basis of our previous experience that neo-suspensory commissural chord creation in patients with a BAV who had ruptured their "truncal valve-like" commissural suspensory chords causing severe cusp prolapse failed early on, ${ }^{6,7}$ the analysis was repeated excluding the 2 patients with BAV with neo-suspensory chords. This revealed that preoperative $4+\mathrm{AR}$ and preoperative $\mathrm{AR}$ grade were no longer associated with mild AR progression in the multivariate $(P=.170$ and $P=.313$, respectively $)$ or log-rank $(P=.179$ and .358 , respectively) analyses, but aortic valve repair remained significant $(P=.023$ on multivariate analysis, .019 on log-rank analysis).

\section{Reoperation}

A total of 4 patients $(4 \%)$ required reoperation over a median of $62 \pm 22$ months of follow-up (Table 4): Two patients with greater than moderate $\mathrm{AR}$ on the 1-year TTE had progression to $3+$ or $4+$ AR 11 months after V-SARR, 1 patient with mild AR on the 1-year TTE had 
TABLE 2. Intraoperative data

\begin{tabular}{|c|c|c|c|c|}
\hline & Total cohort (96 patients) & No early AR $(47,49 \%)$ & Mild early AR (41, 43\%) & $P$ value \\
\hline Prerepair aortic valve annular diameter $(\mathrm{cm})$ & $28 \pm 3(26-29)$ & $28 \pm 3(27-29)$ & $27 \pm 3(25-29)$ & .890 \\
\hline Postrepair aortic valve annular diameter $(\mathrm{cm})$ & $24 \pm 3(21-27)$ & $25 \pm 3(23-27)$ & $23 \pm 3(21-25)$ & .615 \\
\hline Change in aortic valve annular diameter $(\mathrm{cm})$ & $4 \pm 4(0-7)$ & $3 \pm 4(0-6)$ & $4 \pm 4(0-7)$ & .837 \\
\hline $\mathrm{CPB}$ time (min) & $297 \pm 74(250-319)$ & $291 \pm 75(245-305)$ & $304 \pm 77(258-320)$ & .263 \\
\hline Aortic crossclamp time (min) & $232 \pm 55(203-258)$ & $231 \pm 54(197-259)$ & $235 \pm 45(208-255)$ & .252 \\
\hline SACP time $(\min )$ & $29 \pm 10(23-32)$ & $31 \pm 13(22-34)$ & $27 \pm 5(24-30)$ & .395 \\
\hline Axillary/innominate cannulation & $29(30 \%)$ & $13(28 \%)$ & $13(32 \%)$ & .678 \\
\hline Kay-Zubiate & $1(1 \%)$ & $1(2 \%)$ & $0(0 \%)$ & .348 \\
\hline Arch replacement & $30(31 \%)$ & $14(30 \%)$ & $12(29 \%)$ & .958 \\
\hline Concomitant procedures: & & & & .307 \\
\hline Mitral valve repair & $7(7 \%)$ & $3(6 \%)$ & $3(7 \%)$ & \\
\hline PFO closure & $15(16 \%)$ & $8(17 \%)$ & $6(15 \%)$ & \\
\hline Other & $6(6 \%)$ & $2 *(4 \%)$ & $4 \dagger(10 \%)$ & \\
\hline Aortic valve repair: & $49(51 \%)$ & $22(47 \%)$ & $20(49 \%)$ & .701 \\
\hline Free margin shortening & $47(49 \%)$ & $21(45 \%)$ & $19(46 \%)$ & \\
\hline Neo-suspensory chord & $2(2 \%)$ & $0(0 \%)$ & $2(5 \%)$ & \\
\hline Commissuroplasty & $1(1 \%)$ & $1(2 \%)$ & $0(0 \%)$ & \\
\hline Raphé resection & $5(5 \%)$ & $2(4 \%)$ & $1(2 \%)$ & \\
\hline Mild AR on predischarge TTE & $14(15 \%) \ddagger$ & $0(0 \%)$ & $7(17 \%)$ & .003 \\
\hline
\end{tabular}

Data are presented as mean \pm 1 standard deviation with IQR in parentheses. For parametric variables, the total number of patients with the given characteristic is given followed by the percentage of the group in parentheses. The first column lists data for the total study cohort (all 96 patients); data for the "no early AR" and "mild early AR" groups are listed in the following 2 columns. For each group, the number of patients and percentage of the total study cohort ( 96 patients) are indicated in parentheses. $P$ values listed are for the comparisons between the "no early AR" and "mild early AR" groups. Kay-Zubiate is a short interposition saphenous vein graft to coronary ostia. $A R$, Aortic regurgitation; $C P B$, cardiopulmonary bypass; $P F O$, patent foramen ovale; $S A C P$, selective antegrade cerebral perfusion; TTE, transthoracic echocardiogram. *Intra-aortic balloon pump and ventricular assist device in 1 patient and ventricular assist device in 1 patient. $†$ Intra-aortic balloon pump, ventricular assist device, and saphenous vein graft to left anterior descending artery in 1 patient; saphenous vein graft to obtuse marginal in 1 patient; and repair of an anomalous left main with superficial femoral artery autograft in 1 patient; repair of anomalous coronary artery fistula in 1 patient. ‡One patient did not have a predischarge TTE.

progression to $4+$ AR 20 months after V-SARR, and 1 patient who had no AR on a TTE 7 months postoperatively thereafter developed fulminant prosthetic endocarditis and presented with 4+ AR 1 month later, requiring replacement with a homograft aortic root.

\section{DISCUSSION}

\section{Incidence of Mild Aortic Regurgitation and Progression}

Mild AR was present on the 1-year TTE in 41 patients $(43 \%)$, but in the majority of these patients $(85 \%)$ the mild AR remained stable thereafter to a median follow-up of $57 \pm 20$ months. Although longer follow-up is clearly needed, these results suggest that mild AR early after V-SARR occurs in a considerable fraction of patients but is unlikely to progress over the mid-term. In fact, only 1 patient $(2 \%)$ progressed to greater than moderate AR.

Although these results are not directly comparable to the elegant statistical modeling analysis from Lübeck by Hanke and colleagues ${ }^{1}$ because of differences in patient substrate, surgical technique (Tirone David-I or Yacoub vs Tirone David-V with Stanford modification), and length of follow-up, the findings in the analysis by Hanke and colleagues $^{1}$ are relevant. In the reimplantation group in the series by Hanke and colleagues, ${ }^{1}$ there were many patients with acute type A aortic dissection (42\%) but none in our study; there also were fewer patients with a BAV $(11 \%$ vs $31 \%)$ or MFS $(20 \%$ vs $41 \%)$ in the series by Hanke and colleagues. ${ }^{1}$ The patients in the Lübeck series also were more likely to have moderate or greater preoperative AR (59\% vs 34\%), and fewer underwent aortic valve repair $(19 \%$ vs $51 \%) .{ }^{1}$ In terms of incidence of AR after V-SARR, the mean predischarge AR grade in the reimplantation group in the report by Hanke and colleagues $^{1}$ was $0.336 \pm 0.048$ (mean \pm standard error); although the number of patients with early mild AR was not reported explicitly, on the basis of the standard error, there were very few patients with mild AR on discharge,

TABLE 3. Timing of postoperative transthoracic echocardiogram

\begin{tabular}{|c|c|c|c|c|}
\hline & Total cohort (96 patients) & No early AR $(47,49 \%)$ & Early mild AR $(41,43 \%)$ & $P$ value \\
\hline Timing of 1-y TTE (mo) & $12 \pm 4(9-14)$ & $12 \pm 4(8-14)$ & $12 \pm 4(9-14)$ & .951 \\
\hline Timing of most recent TTE (mo) & $62 \pm 22(45-82)$ & $74 \pm 21(49-87)$ & $53 \pm 20(39-74)$ & .008 \\
\hline
\end{tabular}

Data are presented as median months \pm 1 standard deviation after V-SARR. The first column lists timing for the total study cohort (all 96 patients); data for the "no early AR" and "mild early AR" groups are listed in the following 2 columns. For each group, the number of patients and percentage of the total study cohort (96 patients) are indicated in parentheses. $P$ values listed are for the comparisons between the "no early AR" and "mild early AR" groups. AR, Aortic regurgitation; TTE, transthoracic echocardiogram. 


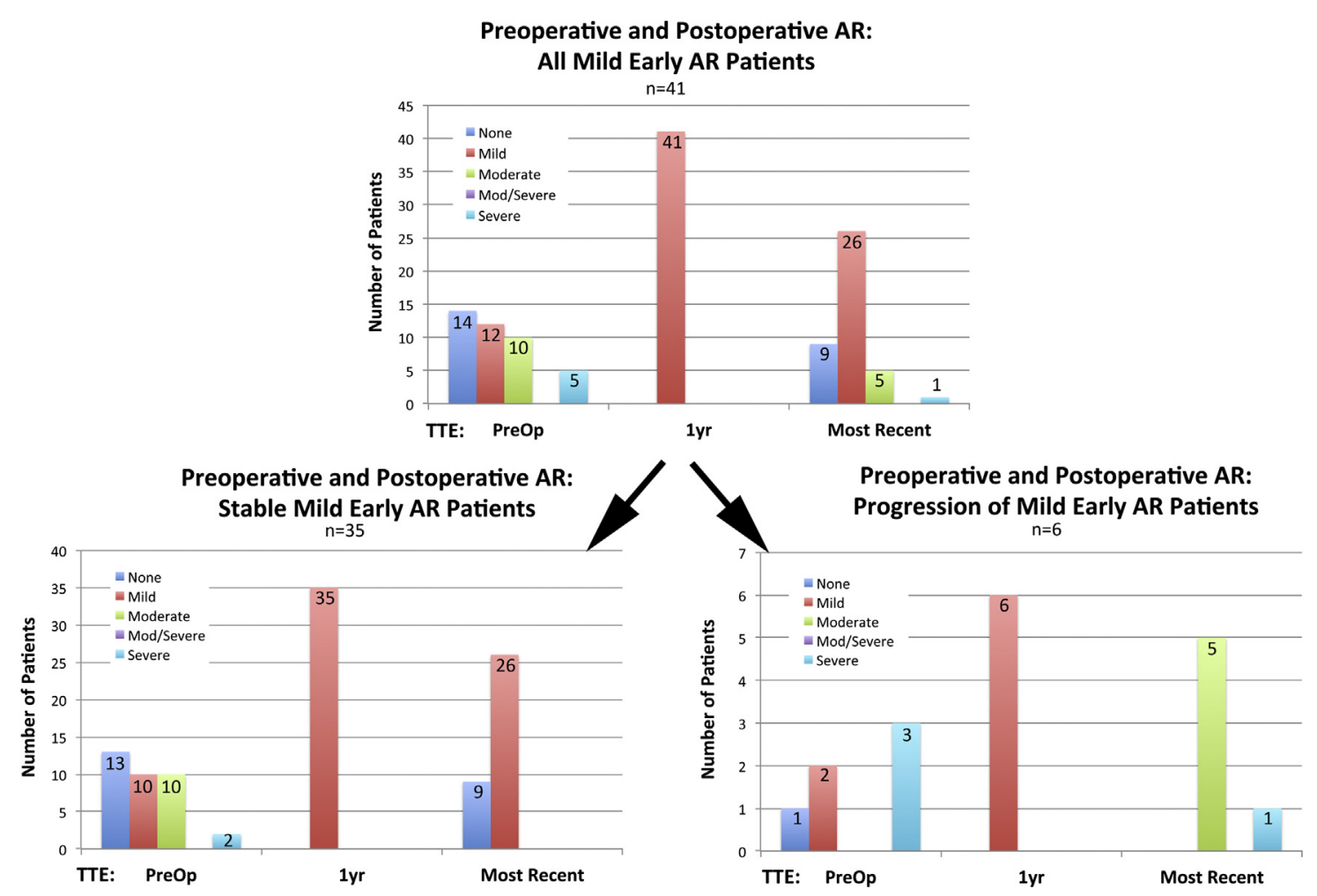

FIGURE 1. AR grade on preoperative and postoperative (1 year and most recent) TTE for all patients in the "mild early AR" subgroup ( $\mathrm{n}=41$ ). Daughter graphs demonstrate the corresponding data for "mild stable AR" ( $(\mathrm{n}=35)$ and "progression of mild AR" (n = 6) subsets. AR, Aortic regurgitation; TTE, transthoracic echocardiogram.

probably less than the $15 \%$ with mild AR at discharge in our study. Over the follow-up period (mean $3.09 \pm 2.92$ years) in the Lübeck series, ${ }^{1}$ mild AR developed in $25 \%$ of the reimplantation group, considerably less than found in the present study. By using linear fits for their data using an average of 3 time points and then assuming a linear increase in AR over the ensuing years, the authors postulated the average AR grade at 10 years in the reimplantation group would be approximately $0.75 .{ }^{1}$ This linear extrapolation has not been validated; further, our observations suggest that AR after V-SARR does not progress linearly because the majority of our patients who had mild AR at 1 year remained stable over a median follow-up of $57 \pm 20$ months. Additional long-term follow-up is needed to answer the question about 10-year and beyond durability.

TABLE 4. Patients requiring reoperation

\begin{tabular}{|c|c|c|c|c|c|c|c|}
\hline Patient & $\begin{array}{c}\text { Preoperative } \\
\text { AR } \\
\end{array}$ & $\begin{array}{c}\text { Age, } \\
\text { gender }\end{array}$ & BAV, CTD & Notes on procedure & $\begin{array}{c}\text { Pre- and post-aortic } \\
\text { valve annular } \\
\text { diameter }(\mathrm{cm}) \\
\end{array}$ & $\begin{array}{c}\text { AR on } \\
\text { 1-y TTE }\end{array}$ & $\begin{array}{c}\text { Time to } 3+/ 4+ \\
\text { AR (mo) } \\
\end{array}$ \\
\hline Patient 1 & 4 & $11, \mathrm{M}$ & MFS & $\begin{array}{l}\text { MV repair (ring annuloplasty, } \\
\text { double Alfieri*), AV repair } \\
\text { (FM shortening) }\end{array}$ & 31,23 & 4 & 11 \\
\hline Patient 2 & 4 & $18, \mathrm{M}$ & MFS & & 47,25 & 3 & 11 \\
\hline Patient 3 & 4 & $27, \mathrm{M}$ & $\begin{array}{l}\text { BAV (Sievers and } \\
\text { Schmidtke 1-L-R) }\end{array}$ & $\begin{array}{l}\text { AV repair (suture closure of raphé } \\
\text { within L cusp of fused L-R, } \\
\text { neo-suspensory chord) }\end{array}$ & 31,27 & 1 & 20 \\
\hline Patient 4 & 4 & $44, \mathrm{M}$ & $\begin{array}{l}\text { BAV (Sievers and } \\
\text { Schmidtke 1-L-R) }\end{array}$ & $\begin{array}{l}\text { AV repair (free margin } \\
\text { shortening), arch }\end{array}$ & 26,27 & 0 & $8 \dagger$ \\
\hline
\end{tabular}




\section{Role of Aortic Valve Repair}

In patients with good cusp quality, minimal calcification (especially important in patients with BAV), and adequate cusp motility, we continue to perform aortic valve repair. After the dilated annulus is downsized, cusp prolapse frequently is induced; we usually correct this with cusp free margin shortening using 6-0 or 5-0 polytetrafluoroethylene (Gore-Tex; WL Gore \& Associates Inc, Flagstaff, Ariz) sutures (7-0 or 8-0 for patients with Loeys-Dietz syndrome) near the nodulus of Aranti in the central belly of the cusp. Cusp repair was performed in $51 \%$ of patients in this report (96\% of repairs included cusp free margin shortening). A key element of successful V-SARR is adequate cusp coaptation. Both the degree of coaptation and the height of coaptation within the graft $^{2,11}$ are important determinants of long-term repair durability. We aim for a 5- to 9-mm cusp coaptation height with the coaptation zone high within the graft.

V-SARR was historically chosen only if there was no severe AR, the annulus was not markedly dilated, the valve was trileaflet, and the cusps were normal; however, over the last decade, repair of abnormal cusps has been pursued more aggressively in attempts to avoid prosthetic valve replacement. ${ }^{2,6,12,13}$ Knowledge of the exact mechanism(s) causing the $\mathrm{AR}$ as promulgated by $\mathrm{EI}$ Khoury and colleagues ${ }^{12}$ guides precise lesion-specific valve and cusp repair strategies, which will hopefully improve outcomes. As Svensson and colleagues ${ }^{13}$ concluded, a pathology-specific approach to valve-sparing operations using reimplantation, remodeling, and sinotubular junction reduction strategies predicated on the specific pathology yields excellent results across a diverse patient population. Employing aortic valve repair techniques in the context of reimplantation, several authors have concluded that concomitant aortic valve repair is not a risk factor portending higher reoperation rates. ${ }^{6,14,15}$ However, other series have identified aortic valve repair as a risk factor for reoperation, including Pacini and colleagues ${ }^{16}$ and Hanke and colleagues ${ }^{1}$ (who used central plication with pericardial pledgets for cusp repair). Oka and colleagues $^{3}$ reported that certain cusp repairs, including commissure repair and repair of thin cusps, led to worse outcomes, emphasizing the importance of understanding the intricacies and limitations of cusp repair. On the basis of currently available clinical data, it is difficult to identify a priori in advance in which individuals one should not attempt to preserve the valve; however, as promulgated by David and colleagues, ${ }^{14}$ we advocate that valves should be spared only if there is good cusp integrity. Continued technical refinement of repair techniques is ongoing, and more remains to be learned; for example, because of failure within 2 years after polytetrafluoroethylene (Gore-Tex; WL Gore \& Associates Inc, Flagstaff, Ariz) suture replacement of ruptured truncal "commissural suspensory chords" in a patient with BAV, we have been hesitant to use this technique. ${ }^{6,7}$ Triangular raphé resection and cusp plication is avoided if possible because these maneuvers limit cusp mobility. ${ }^{7}$ Although aortic valve repair was associated with progression of mild AR in the present study, in all except 1 patient the AR progressed to only $2+$, which remained stable over the next 5 to 6 years. It should be noted that in the entire Stanford experience, valve repair was not a predictor of reoperation or greater than $2+$ AR. $^{6}$ Longer-term follow-up beyond 10 years is essential to learn which valves should be repaired and which replaced.

\section{Influence of Bicuspid Aortic Valve}

Although V-SARR initially was applied only in patients with a trileaflet aortic valve (TAV), over time more valve-preserving procedures have been done in patients with a BAV if they have minimal cusp calcification or fibrosis. ${ }^{14}$ Recent reports demonstrate over the mid-term (5 years) that there are no differences in mortality or reoperation rates after V-SARR in patients with a BAV compared with those with a $\mathrm{TAV}^{6}{ }^{6}$ despite many differences in preoperative and operative characteristics. ${ }^{6}$ The follow-up of patients with BAV after V-SARR is relatively short, however, and it is not realistic to expect BAVs to function satisfactorily as long as normal TAVs in the 20+-year time frame because a BAV can inexorably become fibrotic and calcified and eventually stenotic. Hanke and colleagues ${ }^{1}$ did not identify BAV as a risk factor for AR after V-SARR (only $11 \%$ of the patients in the Lübeck series had a BAV), but follow-up was short. Seasoned judgment and ample experience are mandatory to determine which BAV cusps are suitable for V-SARR; at Stanford, BAV cusps with significant fibrosis or calcification are replaced. At this time, the presence of a BAV apparently cannot be linked to progression of mild AR over the mid-term, which justifies continuing to preserve good-quality BAVs in young patients.

\section{Impact of Connective Tissue Disorder}

Given the proven long-term durability of a CVG incorporating a mechanical prosthesis along with minimal morbidity and mortality in young patients with MFS or other $\mathrm{CTD}^{17}$ and the unknown long-term durability of V-SARR in these patients, surgeons initially were reluctant to offer V-SARR to those with MFS or other CTD. Over the last 2 decades, however, the use of V-SARR in patients with CTD has increased considerably, in part because of patient demand and their desire to avoid lifelong anticoagulation. Data continue to accrue regarding the durability of V-SARR in these patients, but the long-term results still remain unknown; 10-year data from the Stanford overall 
experience showed no difference in need for reoperation between patients with and without $\mathrm{CTD},{ }^{6}$ consistent with the results of Shrestha and colleagues. ${ }^{2}$ In fact, the most recent analysis of David and colleagues ${ }^{14}$ V-SARR series (mean follow-up 6.9 years, 36\% with MFS) found MFS to be protective from death, probably because of the younger age of the patients with MFS. However, it is important to note that there were only 62 patients remaining at risk at 10 years and 21 patients at 14 years. An analysis from the Homburg group ${ }^{18}$ similarly suggested V-SARR in patients with MFS might have superior event-free survival compared with a CVG. In the report by Hanke and colleagues, ${ }^{1}$ however, MFS was a risk factor for AR progression using the remodeling or the reimplantation techniques. The National Marfan Foundation Aortic Root Registry Study (Aortic Valve Operative Outcomes in Marfan Patients) enrolled 316 patients meeting rigorous Ghent criteria for MFS from 19 centers (15 in North America) and currently is assessing the outcomes of V-SARR versus CVG out to 10 years to address this unanswered question. ${ }^{19}$

\section{Preoperative Annular Diameter and Degree of Preoperative Aortic Regurgitation}

Preoperative annular diameter and the magnitude of annular reduction have been associated with recurrent AR and reoperation in some reports, ${ }^{1,20,21}$ including our recent analysis of V-SARR for $\mathrm{BAV}^{7}$ In the present 2003-2008 cohort, in the analysis of the complete Stanford V-SARR experience from 1993 to $2009,{ }^{6}$ and the series by Leyh and colleagues, ${ }^{22}$ however, no adverse impact was apparent. In the study by Hanke and colleagues, ${ }^{1}$ smaller preoperative diameter was a risk factor for $A R$ in the patients undergoing the David reimplantation, but paradoxically a larger annulus was linked with more late AR in the patients undergoing remodeling. The authors postulated a smaller neo-annular area after reimplantation may have increased turbulent flow and earlier cusp failure leading to AR, but this is speculative.

The association between preoperative grade of AR and recurrent AR after V-SARR continues to be debated. Consonant with the recent analysis of our 1993-2009 overall Tirone David V-SARR experience in which patients with preoperative $4+$ AR were at higher risk for structural valve deterioration and reoperation, ${ }^{6}$ preoperative $4+\mathrm{AR}$ also was a risk factor for progression of early mild AR in the present study. When the 2 BAV patients with neosuspensory chords were excluded, however, preoperative $4+$ AR no longer was a significant risk factor for progression of mild AR, and only 1 patient with progression of early mild AR in this study required reoperation (he had a BAV, 4+ preoperative AR, and neo-suspensory chord repair). Further, our current analysis is limited by the few number of patients with preoperative $4+\mathrm{AR}$ and large variability of the dependent end points. The Hannover group found that preoperative AR was a risk factor for 30-day mortality, but not for reoperation. ${ }^{2}$ Leshnower and colleagues $^{23}$ concluded that $3+$ or greater preoperative AR was not associated with a higher risk of moderate AR postoperatively over the short-term (mean follow-up of 19 months), similar to the findings of Hanke and colleagues ${ }^{1}$ (mean follow-up of 3 years). De Kerchove and colleagues ${ }^{15}$ reported that $3+$ or greater preoperative AR did not increase the likelihood of recurrent $\mathrm{AR}$ or need for reoperation (mean follow-up of 5 years), echoing David and colleagues, ${ }^{14}$ recent findings analyzing David's entire career experience (mean follow-up of 7 years). Valves that are leaking badly can be challenging to repair, and certain repair strategies (eg, creation of commissural neo-suspensory chords, Trussler stitches, and formal cusp plication) may not prove durable. Longer follow-up in larger numbers of patients is required to elucidate the optimal management of patients with preoperative 4+ AR. We have been increasingly selective in performing VSARR on patients with $4+$ preoperative AR, but will do so if the cusps are of good quality with minimal calcification.

\section{Mechanisms of Recurrent Aortic Regurgitation Postoperatively}

Investigation continues regarding the mechanisms responsible for AR after V-SARR. Certain causative factors such as endocarditis and cusp repair failure are well established, but fortunately these are rare. The mechanisms underlying slowly progressive AR, however, are still being elucidated. Creating inadequate coaptation height at operation is likely to lead to AR progression, and cusp coaptation below the level of the annulus also has been implicated. ${ }^{14}$ Progressive cusp degeneration has been noted in a variety of inflammatory or autoimmune diseases in patients after V-SARR. ${ }^{3}$ Theoretically, abnormal perturbation of cusp diastolic closing stresses and abnormal stress distribution due to certain operative techniques, noncompliant fabric grafts, elimination of normal aortic annular 3-dimensional motion, or altered cusp geometry ${ }^{24}$ may contribute to valve degeneration over time. Finally, in patients with BAV, the intrinsic inflammatory and calcification processes may progress despite correction of the valvular hemodynamic abnormality, which can lead to valve failure over the long-term. ${ }^{6,7}$ Progressive annular dilation reducing the height of the cusp coaptation zone has been seen after the Yacoub remodeling technique in patients with MFS, which has prompted most surgeons to abandon the remodeling technique. Paying particularly strict attention to restoring normal valve annular and cusp geometry, ensuring adequate cusp coaptation height high within the graft, and being careful regarding repair of thin cusps should minimize late progressive AR after 
V-SARR, but further research clarifying the specific mechanisms underlying deterioration of these valves is needed.

According to the 2008 version of the American Association for Thoracic Surgery/Society of Thoracic Surgeons/European Association for Cardio-Thoracic Surgery valve-reporting guidelines, ${ }^{25}$ residual or recurrent $1+$ AR is considered "nonstructural valve dysfunction." Conversely, Akins and colleagues ${ }^{25}$ stipulated that $1+$ or mild mitral regurgitation after open surgical or catheter interventional mitral repair was not nonstructural valve dysfunction. On the basis of the benign prognosis of mild AR after V-SARR observed in this analysis, we suggest that the next iteration of the valve-reporting guidelines be modified to include only $2+$ or greater AR after aortic valve repair or V-SARR as nonstructural valve dysfunction.

\section{Study Limitations}

This is a single institution analysis examining only a 5 -year interval selected to provide mid-term follow-up. The beginning of the sample window (2003) was chosen on the basis of when we began using the "Tirone David-V Stanford Modification V-SARR" procedure. With the exception of the incidence of preoperative aortic dissection and the use of Kay-Zubiate coronary reconstruction (Tables E1 and E2), there were no significant differences in preoperative and intraoperative characteristics between the patients who had serial TTEs available for analysis allowing for their inclusion in the study and those who did not. Longer follow-up in larger numbers of patients is obviously needed to determine the long-term clinical consequences of early mild AR observed at 1 year. With so few adverse events (progression of mild $\mathrm{AR}$ ), we were unable to perform a meaningful Cox proportional-hazards analysis to calculate hazard ratios, compare the relative predictive values of factors, or identify interactions between variables.

\section{CONCLUSIONS}

Although mild AR frequently occurs early after V-SARR, this mild AR remained stable over the next 5 years in the majority of patients. The need for aortic valve repair and degree of preoperative AR were possibly associated with progression of mild, early AR; however, AR progression was almost exclusively from mild to $2+$ (moderate) AR. Longer follow-up is required to determine the long-term clinical implications of this mild AR early after V-SARR.

The authors thank Arlene Correa, $\mathrm{PhD}$, for consultation regarding statistical analysis; Sunny Pellone, Kathleen Gallagher, and Zoe Magee for assistance in obtaining TTEs; and Allan Paloma for assistance in digitizing TTEs.

\section{References}

1. Hanke T, Charitos EI, Stierle U, Robinson D, Gorski A, Sievers HH, et al. Factors associated with the development of aortic valve regurgitation over time after two different techniques of valve-sparing aortic root surgery. J Thorac Cardiovasc Surg. 2009;137:314-9.

2. Shrestha M, Baraki H, Maeding I, Fitzner S, Sarikouch S, Khaladj N, et al. Long-term results after aortic valve-sparing operation (David I). Eur J Cardiothorac Surg. 2012;41:56-62.

3. Oka T, Okita Y, Matsumori M, Okada K, Minami H, Munakata H, et al. Aortic regurgitation after valve-sparing aortic root replacement: modes of failure. Ann Thorac Surg. 2011;92:1639-44.

4. Tanaka H, Ogino H, Matsuda H, Minatoya K, Sasaki H, Iba Y. Midterm outcome of valve-sparing aortic root replacement in inherited connective tissue disorders. Ann Thorac Surg. 2011;92:1646-50.

5. Perry GJ, Helmcke F, Nanda NC, Byard C, Soto B. Evaluation of aortic insufficiency by Doppler color flow mapping. J Am Coll Cardiol. 1987;9: 952-9.

6. Kvitting JP, Kari FA, Fischbein MP, Liang DH, Beraud AS, Stephens EH, et al. David valve-sparing aortic root replacement: equivalent mid-term outcome for different valve types with or without connective tissue disorder. $J$ Thorac Cardiovasc Surg. 2012;145:117-26. 127.e111-15; discussion 126-7.

7. Kari FA, Liang DH, Kvitting JPE, Stephens EH, Mitchell RS, Fischbein MP, et al. Tirone David valve-sparing aortic root replacement and cusp repair for bicuspid aortic valve disease. J Thorac Cardiovasc Surg. 2013;S35-40.

8. Demers P, Miller DC. Simple modification of "T. David-V" valve-sparing aortic root replacement to create graft pseudosinuses. Ann Thorac Surg. 2004;78: $1479-81$.

9. Itoh A, Fischbein M, Arata K, Miller DC. "Peninsula-style" transverse aortic arch replacement in patients with bicuspid aortic valve. Ann Thorac Surg. 2010;90:1369-71.

10. Sievers HH, Schmidtke C. A classification system for the bicuspid aortic valve from 304 surgical specimens. J Thorac Cardiovasc Surg. 2007;133: 1226-33.

11. David TE, Maganti M, Armstrong S. Aortic root aneurysm: principles of repair and long-term follow-up. J Thorac Cardiovasc Surg. 2010;140:S14-9; discussion S45-51.

12. El Khoury G, Glineur D, Rubay J, Verhelst R, d'Acoz Y, Poncelet A, et al. Functional classification of aortic root/valve abnormalities and their correlation with etiologies and surgical procedures. Curr Opin Cardiol. 2005;20:115-21.

13. Svensson LG, Batizy LH, Blackstone EH, Gillinov AM, Moon MC, D'Agostino RS, et al. Results of matching valve and root repair to aortic valve and root pathology. J Thorac Cardiovasc Surg. 2011;142:1491-98.e1497.

14. David TE, Armstrong S, Manlhiot C, McCrindle BW, Feindel CM. Long-term results of aortic root repair using the reimplantation technique. J Thorac Cardiovasc Surg. 2013; 145:S22-5.

15. de Kerchove L, Boodhwani M, Glineur D, Poncelet A, Verhelst R, Astarci P, et al. Effects of preoperative aortic insufficiency on outcome after aortic valve-sparing surgery. Circulation. 2009;120:S120-6.

16. Pacini D, Settepani F, De Paulis R, Loforte A, Nardella S, Ornaghi D, et al. Early results of valve-sparing reimplantation procedure using the Valsalva conduit: a multicenter study. Ann Thorac Surg. 2006;82:865-72.

17. Cameron DE, Alejo DE, Patel ND, Nwakanma LU, Weiss ES, Vricella LA, et al. Aortic root replacement in 372 Marfan patients: evolution of operative repair over 30 years. Ann Thorac Surg. 2009;87:1344-50.

18. Bernhardt AM, Treede H, Rybczynski M, Sheikzadeh S, Kersten JF, Meinertz T, et al. Comparison of aortic root replacement in patients with Marfan syndrome. Eur J Cardiothorac Surg. 2011;40:1052-7.

19. Volguina IV, Miller DC, LeMaire SA, Palmero LC, Wang XL, Connolly HM, et al. Valve-sparing and valve-replacing techniques for aortic root replacement in patients with Marfan syndrome: analysis of early outcome. J Thorac Cardiovasc Surg. 2009;137:1124-32.

20. Aicher D, Kunihara T, Abou Issa O, Brittner B, Graber S, Schafers HJ. Valve configuration determines long-term results after repair of the bicuspid aortic valve. Circulation. 2011;123:178-85.

21. Kunihara T, Aicher D, Rodionycheva S, Groesdonk HV, Langer F, Sata F, et al. Preoperative aortic root geometry and postoperative cusp configuration primarily determine long-term outcome after valve-preserving aortic root repair. $J$ Thorac Cardiovasc Surg. 2012;143:1389-95

22. Leyh RG, Kallenbach K, Karck M, Hagl C, Fischer S, Haverich A. Impact of preoperative aortic root diameter on long-term aortic valve function after valve sparing aortic root reimplantation. Circulation. 2003;108(Suppl 1):II285-90. 
23. Leshnower BG, Guyton RA, Myung RJ, Puskas JD, Kilgo PD, McPherson L, et al. Expanding the indications for the David $\mathrm{v}$ aortic root replacement: early results. J Thorac Cardiovasc Surg. 2012;143:879-84.

24. Robicsek F, Thubrikar MJ, Fokin AA. Cause of degenerative disease of the trileaflet aortic valve: review of subject and presentation of a new theory. Ann Thorac Surg. 2002;73:1346-54.

25. Akins CW, Miller DC, Turina MI, Kouchoukos NT, Blackstone EH, Grunkemeier GL, et al, Councils of the American Association for Thoracic S, Society of Thoracic S, European Association for Cardio-Thoracic S, Ad Hoc Liaison Committee for Standardizing Definitions of Prosthetic Heart Valve M. Guidelines for reporting mortality and morbidity after cardiac valve interventions. J Thorac Cardiovasc Surg. 2008;135:732-8.

\section{Discussion}

Dr Leonard Girardi (New York, NY). The Stanford group once again should be congratulated on their continued commitment to the analysis and improvement of V-SARR. In the 154 patients they included in this series, $62 \%$ had both 1 - and 5-year followup echocardiography imaging; $43 \%$ of these had aortic insufficiency (AI); $85 \%$, as you said, never progressed any further than mild AI. Of the 5 or 6 who did progress, once they get to $2+$ or moderate AI, again, a gratifying number, $80 \%$ went no further and only 1 subsequently went on to require aortic valve replacement.

In the patients who underwent reoperation, 4 of the 96 , an outstanding rate, 2 additional patients required surgery for valve deterioration. One person developed endocarditis. So only 1 of these patients went from mild AI at 1 year to surgery in the future. The 2 patients who required surgery without endocarditis quickly experienced significant AI.

The indications for this procedure have continuously expanded over the years to an increasingly complex and diverse patient population. No longer are we offering this operation just to young patients with ascending aortic aneurysms, TAVs, and minimal AI. This collection of patients certainly represents what I would think is a "real world" look at aortic root replacement and aortic valve-sparing surgery. It includes patients with bicuspid valves, advanced CTDs, a few aortic dissections, and reoperations. Fifteen percent of their patients had severe AI at the time of surgery.

Despite Dr Miller's extensive experience with this surgery and other root replacement, $43 \%$ had $\mathrm{AI}$ at the time of 1-year follow-up; 17\% had mild AI before they even left the hospital, and this is in extremely experienced hands.

So, again, it is not surprising to me that these patients have AI. These data reassure us that just because you have AI at 1 year, even if it's moderate, all is not lost. This should be reassuring to not only the surgeons performing the surgery but also the cardiologists following them and, most important, the patient. As patients get their echocardiography reports and hear that they have AI, they can go into a tailspin by thinking a reoperation is right around the corner. That clearly is not the case and to me the most important result of this study. I have a number of questions for you.

On your more advanced multivariate analysis, the only risk factor that really was significantly predictive of the need for reoperation was aortic valve repair. I know at least for us at Cornell, one of the problems we have is trying to figure out who really needs valve repair and who doesn't. I question sometimes whether we do too many of them and whether we are actually doing more harm than good. What techniques do you use at Stanford to try to sort out who could benefit from a valve repair and those we should leave alone? Do you have a way to know who they are?

Dr Stephens. Thank you, Dr Girardi, for your excellent questions. Regarding aortic valve repair, we often don't know whether we are going to need to add any cusp repair until that graft is sutured down and the final neo-annular geometry can be appreciated; then we see if we have induced any new prolapse or there was prolapse present before the graft that needs attention. We do not always know ahead of time which patients are going to need aortic cusp repairs.

That said, yes, we continue to do valve-sparing procedures in patients who need cusp repairs. I think it comes down to, as Dr David continues to say, the quality of the cusps. If the cusps are of good quality, and, in particular in the patients with bicuspid valves, have minimal fibrosis or calcification, then we feel we can achieve a durable repair and proceed. This is based on the analysis of the entire Stanford experience that was presented at the American Association for Thoracic Surgery last year in which aortic valve repair was not a predictor of reoperation or recurrent AR. So we have continued to do aortic valve repair, and, as you saw, most frequently it is cusp free margin shortening. The analysis of the entire Stanford experience is consistent with other large series in which aortic valve repair was not a significant predictor of $\mathrm{AR}$ recurrence or reoperation.

Dr Girardi. After you have reimplanted the valve and you look down through and see obvious prolapse, you sort of know it when you see it. But other than those patients, are you waiting until the patient comes off bypass to figure out who needs valve repair? Did you re-clamp and re-pledge, because a lot of these patients have had long crossclamp times, long pump runs, and another period of myocardial ischemia might not be the right thing. Your data would suggest that coming off bypass with a little bit of AI, or maybe even $1-1 / 2+\mathrm{AI}$, is not such a bad thing. We could leave them with that rather than taking the risk of another period of ischemia. Is that how it is done?

Dr Stephens. To address your question of what our limit is in terms of AR coming out of the operating room, we do not leave with anything more than with anything more than trace (or mild at the worst) AR; we always "stress test" the valve by increasing the systolic blood pressures to at least $150 \mathrm{~mm} \mathrm{Hg}$ to see whether the valve leaks. Luckily, in the more than 300 cases that Dr Miller has done since 1993, he has never had to re-crossclamp to re-repair a valve or convert to valve replacement on the table.

Dr Girardi. So experience is more important than anything. Is that what you are saying?

Dr Stephens. Absolutely.

Dr Girardi. Of the patients who did fail, 2 of them had a lot of AI fairly early on, within 1 year, and if you look at the data, which were not presented here because of time constraints, although preoperative annular diameter was not found to be predictive of failure, 2 of those patients had a big annulus. One was a 35- or 34-mm annulus in an 11-year-old, and another had an annulus that was in excess of $40 \mathrm{~mm}$. So it just may be that there is too small of a number to predict valve failure.

If you had to do that again, would those patients still get a valve-sparing root, or are there limits to what you will do? As you said, a CVG after coming off bypass has not been necessary, 
but do you see people in the operating room and say, this isn't going to work?

Dr Stephens. Two points with regard to those excellent questions, the first regarding reoperation. We had 4 reoperations; 1 case was the 11-year-old boy with MFS you mentioned with a huge annulus, very poor tissue integrity, and who also needed a very complicated mitral repair; Dr Miller in hindsight feels saving these valves was a judgment error in this particular patient. Another patient who required reoperation had a BAV and 4+ AR preoperatively; gross prolapse of the fused left-right coronary cusp was due to rupture of truncal-valve type of suspensory chordae in the left-right commissure. He received commissural neosuspensory chords using polytetrafluoroethylene (Gore-Tex; WL Gore \& Associates Inc, Flagstaff, Ariz) suture that pulled out of the tissue after 20 months, leading to acute recurrent $4+$ AR. We have been more hesitant in light of that particular patient to use commissural neo-suspensory polytetrafluoroethylene (Gore-Tex) chords. We learned hard lessons from both of these patients.

Dr Tirone David (Toronto, Ontario, Canada). I don't know how many of you know, but Elizabeth Stephens is a surgical intern. I have to commend her to be brave enough to stand in an audience of mostly men and present us her study.

Elizabeth, aortic valve repair is no different than mitral valve repair and likely the single most important thing, more important than how little the valve is leaking in the operating room is morphology of the cusps when you finish the reimplantation or remodeling. As in mitral valve repair, we talk about leaflets coaptation area, and the coaptation has to be within the ventricle. In the aortic valve, the coaptation has to be within the aortic root. So if the cusps are coapting 4 to $6 \mathrm{~mm}$, and they are $8 \mathrm{~mm}$ inside the aortic root, and there is mild AI, reassure yourself that things will alright for the next 20 years. We have done that, and they seldom fail.

If at the end of the operation the cusps coapt at the level of the annulus or below, it is usually bad news because they will come back with AI. This has been our experience with tricuspid aortic valves. I am a late comer in BAV reimplantation, but Dr Schäfers has more experience than anybody else, and he may say the same for BAVs. Did you look at morphology of the cusps and try to correlate it with AI?

Dr Stephens. We have not looked at morphology.

Dr David. But you have the data, don't you; you have the intraoperative echocardiograms?

\section{Dr Stephens. Yes.}

Dr Hans-Joachim Schäfers (Homburg/Saar, Germany). I would like to repeat the topic that Tirone has started, that is, valve morphology. Multiple series have shown that if you achieve normal valve morphology, the valve will be stable at the end of the operation. There are essentially 2 ways of assessing valve morphology: One is eyeballing, and the other is actual measurement, such as measurement of effective height. What was the primary parameter? Was it eyeballing or some objective measurement, and if so, what?

Dr Stephens. In general, we aim for a goal of 5 to $9 \mathrm{~mm}$ of coaptation height (or "effective coaptation height" as you define it, Dr Schäfers); as Dr David alluded to, that coaptation zone has to be relatively high within the graft, but we have not objectively measured that variable. I don't know if Dr Miller can comment on that.

Dr Miller. Hans-Joachim, we eyeball it and do not have your little J-shaped tool to directly measure "effective coaptation length." Maybe we should. We have tried to estimate coaptation zone height from the postoperative TTEs, but that is probably not terribly accurate. I agree that the geometric principles that Tirone David and you told us about are important.

Thank you, Tirone, for pointing out that Elizabeth Stephens is a postgraduate year 1 (intern) at Columbia. If I were an intern up here in front of this audience, I'd be in supraventricular tachycardia with a heart rate over 200 . 
Progression of Mild AR: AV Repair

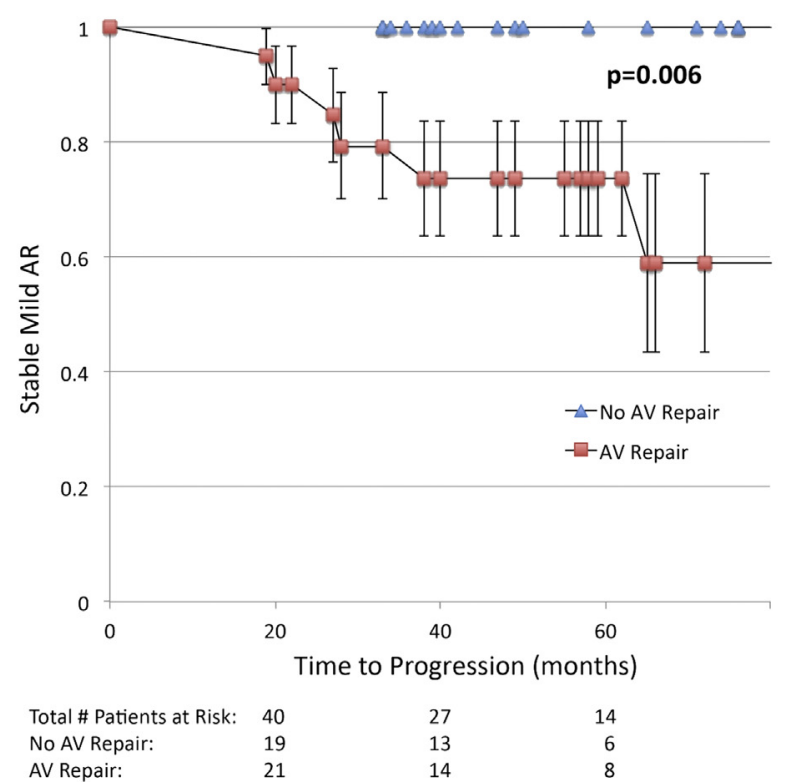

Progression of Mild AR: PreOp AR

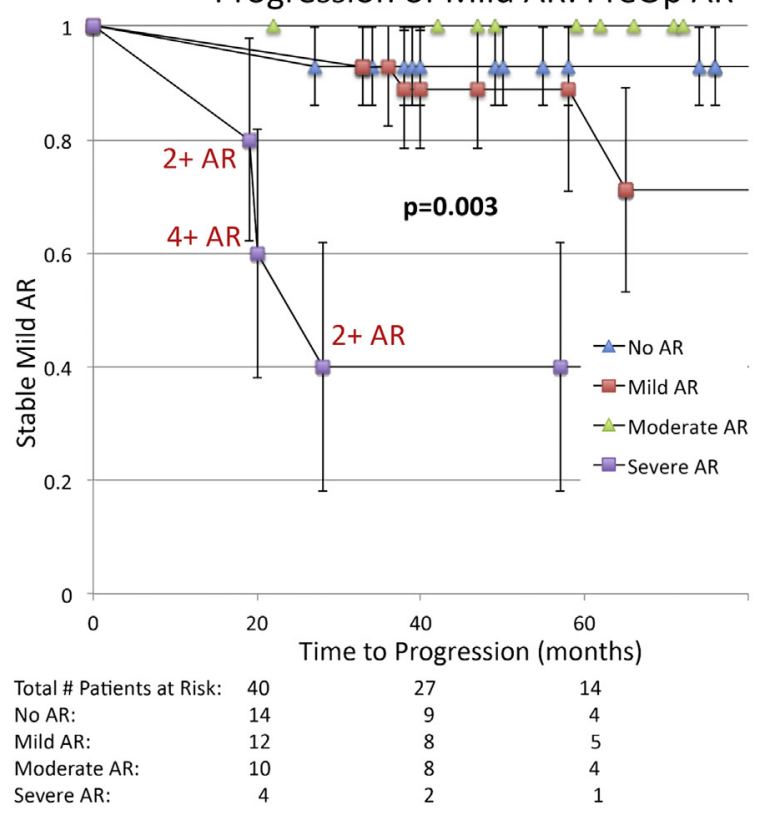

FIGURE E1. A, Log-rank (Mantel-Cox) analysis of progression of AR in patients with mild AR on the 1-year TTE. Error bars indicate standard error of the estimate. Number of patients at risk in each group is listed under the $\mathrm{x}$-axis. Note the relatively few number of patients at risk $(\mathrm{n}=14)$ at $60 \mathrm{months}$. On log-rank analysis, aortic valve repair versus no repair has a $P$ value of .006 . All patients, except 1 with AR that progressed to moderate, remained stable at the time of the latest follow-up echocardiogram. B, Log-rank (Mantel-Cox) analysis of progression of AR in patients with mild AR on the 1-year TTE. Error bars indicate standard error of the estimate. Number of patients at risk in each group is listed under the X-axis. Note the relatively few number of patients at risk (14) at 60 months. On log-rank analysis, preoperative AR grade had a $P$ value of .003 . All patients, except 1 with AR that progressed to moderate, remained stable through the latest follow-up. The red labels on the severe preoperative AR curves indicate the most recent AR grade for the patients in whom AR progressed. The patient with $4+\mathrm{AR}$ ultimately underwent reoperation. $A R$, Aortic regurgitation; $A V$, atrioventricular. 
TABLE E1. Preoperative patient characteristics (2003-2008)

\begin{tabular}{|c|c|c|c|c|}
\hline & Total cohort (154) & AR study cohort $(96,62 \%)$ & $\begin{array}{c}\text { Patients without } 1-y \\
\text { echocardiogram }(58,38 \%)\end{array}$ & $P$ value \\
\hline Age (y) & $38 \pm 13(27-49)$ & $38 \pm 13(27-48)$ & $39 \pm 13(26-49)$ & .616 \\
\hline Gender, male & $113(73 \%)$ & $68(71 \%)$ & $45(78 \%)$ & .358 \\
\hline Weight (lb) & $181 \pm 37(160-202)$ & $179 \pm 41(158-199)$ & $185 \pm 29(162-204)$ & .343 \\
\hline Height (in) & $72 \pm 5(69-75)$ & $72 \pm 5(69-75)$ & $72 \pm 4(69-75)$ & .491 \\
\hline BMI $\left(\mathrm{kg} / \mathrm{m}^{2}\right)$ & $25 \pm 5(22-28)$ & $24 \pm 5(21-28)$ & $26 \pm 4(23-28)$ & .508 \\
\hline $\operatorname{BSA}\left(\mathrm{m}^{2}\right)$ & $2.0 \pm 0.2(1.9-2.2)$ & $2.0 \pm 0.3(1.9-2.2)$ & $2.0 \pm 0.2(1.9-2.2)$ & .342 \\
\hline BAV (Sievers and Schmidtke type): & $49(32 \%)$ & $30(31 \%)$ & $19(33 \%)$ & .846 \\
\hline $0-\mathrm{AP}$ & $6(4 \%)$ & $4(4 \%)$ & $2(3 \%)$ & \\
\hline 0-LAT & $9(6 \%)$ & $3(3 \%)$ & $6(10 \%)$ & \\
\hline 1-L-R & $31(20 \%)$ & $21(22 \%)$ & $10(17 \%)$ & \\
\hline $1-\mathrm{N}-\mathrm{L}$ & $1(1 \%)$ & $1(1 \%)$ & $0(0 \%)$ & \\
\hline $0-\mathrm{R}-\mathrm{N}$ & $2(1 \%)$ & $1(1 \%)$ & $1(2 \%)$ & \\
\hline CTD: & $65(42 \%)$ & $41(43 \%)$ & $24(41 \%)$ & .504 \\
\hline MFS & $60(39 \%)$ & $39(41 \%)$ & $21(36 \%)$ & \\
\hline Loeys-Dietz syndrome & $5(3 \%)$ & $2(2 \%)$ & $3(5 \%)$ & \\
\hline Preoperative AR: & & & & .713 \\
\hline None/trivial & $40(26 \%)$ & $29(30 \%)$ & $11(19 \%)$ & \\
\hline Mild (1+) & $30(19 \%)$ & $17(18 \%)$ & $13(22 \%)$ & \\
\hline Moderate $(2+)$ & $15(10 \%)$ & $0(0 \%)$ & $15(26 \%)$ & \\
\hline Moderate-Severe $(3+)$ & $15(10 \%)$ & $0(0 \%)$ & $15(26 \%)$ & \\
\hline Severe $(4+)$ & $20(13 \%)$ & $14(14 \%)$ & $6(10 \%)$ & \\
\hline LVEF $(\%)$ & $61 \pm 6(60-65)$ & $61 \pm 6(58-65)$ & $61 \pm 6(60-65)$ & .425 \\
\hline Aortic dissection & $6(4 \%)$ & $1(1 \%)$ & $5(9 \%)$ & .019 \\
\hline Previous cardiac surgery & $6(4 \%)$ & $2(2 \%)$ & $4(7 \%)$ & .135 \\
\hline \multicolumn{5}{|c|}{$\begin{array}{l}\text { Data are presented as mean } \pm 1 \text { standard deviation with IQR in parentheses. For parametric variables, the total number of patients with the given characteristic is given followed by } \\
\text { the percentage of the group in parentheses. The first column lists data for all patients undergoing V-SARR at Stanford from } 2003 \text { to } 2008 \text {, the second column lists data for the } \\
\text { subgroup of patients with } 1 \text {-year follow-up echocardiograms included in the present study, and the third column lists data for the remaining patients for whom no } 1 \text {-year follow-up } \\
\text { echocardiogram was available and who were excluded from the present study. } P \text { values listed are for the comparisons between the patients included in the present study and those } \\
\text { excluded. BAVs were classified using the system by Sievers and Schmidtke, }{ }_{10}^{10} \text { where } O \text { indicates no raphé and includes the subtypes of } 0 \text {-AP and } 0 \text {-LAT, and } 1 \text { indicates } 1 \text { raphé } \\
\text { and includes the subtypes of } 1-\mathrm{L}-\mathrm{R}, 1-\mathrm{N}-\mathrm{L} \text {, and } 1-\mathrm{R}-\mathrm{N} \text {. } A P \text {, Anterior-posterior; } A R \text {, aortic regurgitation; } B A V \text {, bicuspid aortic valve; } B M I \text {, body mass index; } B S A \text {, body surface area; } \\
C T D \text {, connective tissue disorder; } L A T \text {, lateral; } L V E F \text {, left ventricular ejection fraction; } M F S \text {, Marfan syndrome; } 1-N-L \text {, noncoronary cusp and left coronary cusp fusion; } 1-L-R \text {, left- } \\
\text { right coronary cusp fusion; } 1-R-N \text {, right coronary cusp and noncoronary cusp fusion. }\end{array}$} \\
\hline
\end{tabular}


TABLE E2. Intraoperative data: Total cohort 2003-2008

\begin{tabular}{|c|c|c|c|c|}
\hline & Total cohort (154) & AR study cohort $(96,62 \%)$ & $\begin{array}{c}\text { Patients without 1-y } \\
\text { echocardiogram }(58,38 \%)\end{array}$ & $P$ value \\
\hline $\begin{array}{l}\text { Prerepair aortic valve annular } \\
\text { diameter }(\mathrm{cm})\end{array}$ & $28 \pm 4(26-29)$ & $28 \pm 3(26-29)$ & $27 \pm 2(25-29)$ & .780 \\
\hline $\begin{array}{l}\text { Postrepair aortic valve } \\
\text { annular diameter }(\mathrm{cm})\end{array}$ & $22 \pm 2(21-23)$ & $24 \pm 3(21-27)$ & $22 \pm 2(21-23)$ & .754 \\
\hline $\begin{array}{l}\text { Change in aortic valve annular } \\
\text { diameter }(\mathrm{cm})\end{array}$ & $6 \pm 3(4-8)$ & $4 \pm 4(0-7)$ & $6 \pm 2(4-8)$ & .644 \\
\hline CPB time (min) & $298 \pm 66(255-323)$ & $297 \pm 74(250-319)$ & $300 \pm 50(259-325)$ & .847 \\
\hline Aortic crossclamp time (min) & $235 \pm 50(204-260)$ & $232 \pm 55(203-258)$ & $240 \pm 41(203-262)$ & .728 \\
\hline SACP time (min) & $29 \pm 11(23-32)$ & $29 \pm 10(23-32)$ & $29 \pm 13(23-29)$ & .944 \\
\hline $\begin{array}{l}\text { Axillary/innominate } \\
\text { cannulation }\end{array}$ & $52(34 \%)$ & $29(30 \%)$ & $23(40 \%)$ & .230 \\
\hline Kay-Zubiate & $5(3 \%)$ & $1(1 \%)$ & $4(7 \%)$ & .047 \\
\hline Arch replacement & $53(34 \%)$ & $30(31 \%)$ & $23(40 \%)$ & .287 \\
\hline Concomitant procedures: & & & & .099 \\
\hline Mitral valve repair & $10(6 \%)$ & $7(7 \%)$ & $3(5 \%)$ & \\
\hline PFO closure & $23(15 \%)$ & $17(18 \%)$ & $8(14 \%)$ & \\
\hline Other & $7(3 \%)$ & $6(6 \%)$ & $1(2 \%)$ & \\
\hline Aortic valve repair: & $81(53 \%)$ & $49(51 \%)$ & $32(55 \%)$ & .619 \\
\hline Free margin shortening & $80(52 \%)$ & $48(50 \%)$ & $32(55 \%)$ & \\
\hline Neo-suspensory chord & $4(3 \%)$ & $3(3 \%)$ & $1(2 \%)$ & \\
\hline Commissuroplasty & $1(1 \%)$ & $1(1 \%)$ & $0(0 \%)$ & \\
\hline Raphé resection & $7(5 \%)$ & $5(5 \%)$ & $2(3 \%)$ & \\
\hline
\end{tabular}

Data are presented as mean \pm 1 standard deviation with IQR in parentheses. For parametric variables, the total number of patients with the given characteristic is given followed by the percentage of the group in parentheses. The first column lists data for all patients undergoing V-SARR at Stanford from 2003 to 2008, the second column lists data for the subgroup of patients with a 1-year follow-up echocardiogram and therefore were included in the present study, and the third column lists data for the remaining patients for whom no 1-year follow-up echocardiogram was available and who were excluded from the present study. $P$ values listed are for the comparisons between the patients included and excluded in the present study. Kay-Zubiate is a short interposition saphenous vein graft to coronary ostia. $A R$, Aortic regurgitation; $C P B$, cardiopulmonary bypass; $P F O$, patent foramen ovale repair; $S A C P$, selective antegrade cerebral perfusion. 